\title{
Diagnostic accuracy of loop-mediated isothermal amplification (LAMP) for screening patients with imported malaria in a non-endemic setting
}

\author{
Camille Ponce $^{1, a}$, Flora Kaczorowski ${ }^{1, a}$, Thomas Perpoint ${ }^{2}$, Patrick Miailhes $^{2}$, Alain Sigal ${ }^{3}$, Etienne Javouhey ${ }^{4}$, \\ Yves Gillet $^{4}$, Laurent Jacquin ${ }^{5}$, Marion Douplat ${ }^{6}$, Karim Tazarourte ${ }^{7,8}$, Véronique Potinet ${ }^{6}$, Bruno Simon ${ }^{1}$, \\ Adeline Lavoignat ${ }^{9}$, Guillaume Bonnot ${ }^{9}$, Fatimata Sow ${ }^{9}$, Anne-Lise Bienvenu $^{9,10}$, and Stéphane Picot ${ }^{1,9}{ }^{*}$ \\ ${ }^{1}$ Institute of Parasitology and Medical Mycology, Hôpital de la Croix-Rousse, Hospices Civils de Lyon, 69004 Lyon, France \\ 2 Service des Maladies Infectieuses et Tropicales, Hôpital de la Croix-Rousse, Hospices Civils de Lyon, 69004 Lyon, France \\ ${ }^{3}$ Service d'accueil des Urgences, Hôpital de la Croix-Rousse, Hospices Civils de Lyon, 69004 Lyon, France \\ 4 Service d'accueil des Urgences Pédiatriques, Hôpital Femme-Mère-Enfant, Hospices Civils de Lyon, 69677 Bron, France \\ ${ }^{5}$ Service d'accueil des urgences, Hôpital Edouard Herriot, Hospices Civils de Lyon, 69003 Lyon, France \\ ${ }^{6}$ Service d'accueil des urgences, Hôpital Lyon Sud, Hospices Civils de Lyon, Hôpital Lyon Sud, 69310 Pierre-Bénite, France \\ 7 Service des urgences/SAMU 69, Hospices Civils de Lyon, Lyon, 69003, France \\ 8 Univ. Lyon, Université Claude Bernard Lyon 1, HESPER EA 7425, 69008 Lyon, France \\ ${ }^{9}$ Malaria Research Unit, SMITh, ICBMS, UMR 5246 CNRS-INSA-CPE-University Lyon1, 69100 Villeurbanne, France \\ ${ }^{10}$ Laboratoire d'Hématologie, Hôpital de la Croix-Rousse, Hospices Civils de Lyon, 69004 Lyon, France
}

Received 31 August 2017, Accepted 29 November 2017, Published online 18 December 2017

\begin{abstract}
Background: Sensitive and easy-to-perform methods for the diagnosis of malaria are not yet available. Improving the limit of detection and following the requirements for certification are issues to be addressed in both endemic and non-endemic settings. The aim of this study was to test whether loop-mediated isothermal amplification of DNA (LAMP) may be an alternative to microscopy or real-time PCR for the screening of imported malaria cases in non-endemic area. Results: 310 blood samples associated with 829 suspected cases of imported malaria were tested during a one year period. Microscopy (thin and thick stained blood slides, reference standard) was used for the diagnosis. Real-time PCR was used as a standard of truth, and LAMP (Meridian Malaria Plus) was used as an index test in a prospective study conducted following the Standards for Reporting Diagnosis Accuracy Studies. In the 83 positive samples, species identification was $P$. falciparum $(\mathrm{n}=66), P$. ovale $(\mathrm{n}=9), P$. vivax $(\mathrm{n}=3) P$. malariae $(\mathrm{n}=3)$ and 2 co-infections with $P$. falciparum + P.malariae. Using LAMP methods, 93 samples gave positive results, including 4 false-positives. Sensitivity, specificity, positive predictive value and negative predictive value for LAMP tests were $100 \%$, 98.13\%, 95.51\%, and 100\% compared to PCR. Conclusion: High negative predictive value, and limit of detection suggest that LAMP can be used for screening of imported malaria cases in non-endemic countries when expert microscopists are not immediately available. However, the rare occurrence of non-valid results and the need for species identification and quantification of positive samples preclude the use of LAMP as a single reference method.
\end{abstract}

Keywords: Malaria, diagnosis, Plasmodium, isothermal amplification, LAMP, microscopy

Résumé-Précision diagnostique de l'amplification isothermique d'ADN en boucle (LAMP) pour le dépistage des patients avec paludisme importé dans un contexte non endémique. Contexte : Des méthodes sensibles et faciles pour le diagnostic du paludisme sont encore attendues. Améliorer la limite de détection et répondre aux besoins de la certification sont des questions auxquelles il faut répondre tant en zone endémique que non-endémique. L'objectif de cette étude était de tester si la méthode d'amplification isothermique d'ADN en boucle (LAMP) peut être une alternative à la microscopie ou à la PCR temps réel pour le dépistage des cas de paludisme d'importation en zone non-endémique. Résultats : 310 échantillons de sang provenant de 829 suspicions de paludisme importé ont été testés pendant l'année de l'étude. La microscopie

\footnotetext{
*Corresponding author: Stephane.picot@univ-lyon1.fr
}

These two authors contributed equally to the study

This is an Open Access article distributed under the terms of the Creative Commons Attribution License (http://creativecommons.org/licenses/by/4.0), which permits unrestricted use, distribution, and reproduction in any medium, provided the original work is properly cited. 
(frottis sanguins et gouttes épaisses colorées, standard de référence) a été utilisée pour le diagnostic. La PCR temps réel a été utilisée comme standard de vérité, et la LAMP (Meridian Malaria Plus) a été utilisée en méthode index dans une étude prospective conduite selon les standards pour rapporter les études d'efficacité diagnostique. Parmi les 83 échantillons positifs, l'identification des espèces était $P$. falciparum $(\mathrm{n}=66), P$. ovale $(\mathrm{n}=9), P$. vivax $(\mathrm{n}=3) P$. malariae $(\mathrm{n}=3)$ et 2 coïnfections $P$. falciparum $+P$. malariae. La méthode LAMP a donné 93 échantillons positifs, dont 4 faux positifs. La sensitivité, la spécificité, la valeur prédictive positive et la valeur prédictive négative pour le LAMP étaient 100\%,98.13\%,95.51\%, $100 \%$ comparées à la PCR. Conclusion: Une valeur prédictive négative élevée et la limite de détection suggèrent que le LAMP peut être utilisé pour dépister les cas de paludisme d'importation en zone non-endémique lorsque des microscopistes experts ne sont pas immédiatement disponibles. Cependant, la rare possibilité de résultats non valides et le besoin d'une identification d'espèce et d'une quantification empêchent que la méthode LAMP soit utilisée comme seule méthode de référence.

\section{Introduction}

The global malaria burden has been considerably reduced during the last decade thanks to insecticidetreated bed nets, rapid diagnosis tests (RDTs) and highly effective antimalarial treatment. But malaria remains a substantial global health problem [29] and elimination has been pointed out as a reachable goal in the next few decades [16]. One of the major issues to be addressed on the way toward malaria elimination is the development of a highly sensitive, reliable and easy-to-perform method for the point-of-care diagnosis of malaria [3].

Biological diagnosis of malaria can be conducted using light microscopy, RDTs, PCR, or a combination of these methods. Microscopic examination of Giemsa-stained thick or thin smears was the reference standard all over the world for more than a century. But microscopy is recommended for malaria when its quality can be maintained and strong expertise is available. Unfortunately, in endemic and non-endemic countries, expert malaria microscopists are uncommon in non-specialized clinical laboratories and impaired microscopy-based diagnosis, especially for non-falciparum species, can be suspected [1]. The limit of detection (LOD) may vary substantially depending on the experience and training of microscopists, with a range of 5 to 100 parasites/ $\mu \mathrm{L}$ [31]. The requirements for certification of biological diagnosis have increased the need for efficient and standardized methods that are easy to perform for end-users and that are reliable when microscopic expertise is not immediately available.

Since the early 1990s, the advent of RDTs for malaria [18] has profoundly increased the availability of reliable diagnosis in remote areas. However, the overall sensitivity of most of the RDTs available on the market is high for parasitemia over 200 parasites $/ \mu \mathrm{L}$, but substantially decreased for lower parasite burdens [30]. The molecular detection of malaria parasites has definitively proved its capacity to detect low parasitemia with LOD of 0.05 parasites/ $\mu \mathrm{L}$ or less, depending on many technical factors, including the volume of blood sampled. However, this method is still limited to well-equipped centers mainly outside remote endemic areas and this causes delays that are in conflict with the need for rapid diagnosis to promptly initiate documented treatment of malaria cases.

The recent development of loop-mediated isothermal amplification of DNA (LAMP) in 2000 [17] and its initial application to malaria diagnosis in 2006 [23] mean that it may be a suitable tool for diagnosis in endemic and nonendemic areas $[19,22]$.

LAMP is an isothermal molecular method using a DNA polymerase from Bacillus stearothermophilus which has strand displacement activity leading to DNA autocycling without temperature changes. The different tests available, mostly targeting the mitochondrial genome of the Plasmodium parasite, required a set of six different primers.

The sensitivity and specificity of LAMP have come close to those of PCR [28]. The corresponding naked eye reading makes it a good candidate for field use, although some improvements are still needed. Numerous studies have attempted to address certain weak points by eliminating the need for electricity [14,26], optimizing high throughput $[3,4,6]$, or allowing measurement of parasitemia [12].

The primary objective of this study was to test a LAMP method commercially available (Illumigene Malaria Plus test, Meridian Bioscience Inc., Cincinnati, OH, USA) in daily diagnostic conditions of imported malaria cases in a specialized laboratory of a teaching hospital in a non-endemic area. The secondary objective was to evaluate its relevance as a screening test to be used when expert malaria microscopists are not immediately available. We chose to compare the index test (LAMP), to a reference standard (light microscopy) and to a standard of truth (real-time PCR).

Among a one-year consecutive series of 829 blood samples collected for malaria diagnosis in our institution, 310 fresh blood samples from patients suspected of imported malaria were included. LAMP tests were conducted rapidly after completion of standard diagnostic procedures including microscopic examination of thick and thin blood smears and RDT. Real-time PCR was performed from frozen samples after the initial diagnosis. 
The limit of detection of the Illumigene test was determined using two clones of Plasmodium falciparum cultivated in vitro.

\section{Materials and methods}

\section{Ethical clearance}

This research involved anonymized records and datasets where it is not possible to identify individuals from the information provided. De-identification and removing of protected health information from clinical narratives were performed according to the European Textbook on Ethics in research (http://ec.europa.eu/research/swafs/pdf/ pub_archive/textbook-on-ethics-report_en.pdf). Data used in this study were collected for the routine diagnosis and clinical management of patients at Lyon teaching hospital, and no additional interventions involving patients were planned for research purposes.

\section{Study design}

This was a prospective study conducted according to the Standards for Reporting Diagnosis Accuracy Studies (STARD 2015) [8].

\section{Participants}

Blood samples were collected from all patients suspected of malaria infection at Lyon University Hospital. Eligibility criteria were suspicion of malaria based on fever and history of travel to malaria endemic areas, or history of treated or untreated malaria. Patients were assessed for eligibility and included during a one-year period (June 2016 to June 2017) (Figure 1). Light microscopy (examination of thin and thick blood stains) was used as a reference diagnosis to classify blood as positive or negative for Plasmodium. The final diagnosis was based only on the results of the reference tests. Lamp tests (index test) were conducted from fresh blood samples (stored at $+4{ }^{\circ} \mathrm{C}$ for less than 48 hours) and real-time PCR tests (standard of truth) were conducted from aliquots of samples frozen $\left(-20^{\circ} \mathrm{C}\right)$ after collection. Neither real-time PCR nor LAMP tests were used for clinical malaria diagnosis.

\section{Patient blood samples}

Venous blood samples were collected on EDTA vacutainer tubes and immediately transferred to the laboratory at room temperature. For each blood sample, thin and thick blood stained smears (Diff-Quick and Giemsa stains, respectively) and RDT (Vikia Malaria, BioMérieux, France) [10] were performed in compliance with the recommendations of French guidelines for malaria diagnosis, and following certification requirements of the National Certification Program. Microscopy was performed by two independent trained and certified biologists and discrepancies were resolved by a senior microscopist. The protocol was implemented in accor- dance with standard operating procedures and in compliance with good clinical laboratory practices. Proficiency testing and External Quality Assessment for microscopy were used once a week and bi-monthly, respectively. Parasitemia was recorded as the number of red blood cells (RBCs) infected with asexual parasites compared to noninfected RBCs. Malaria diagnosis was considered to be negative if no parasites were found in 100 microscopic fields of 200 red blood cells for thin smears and 25 microscopic high power fields of thick smears [24]. PCR confirmation was later obtained using real-time PCR, as previously described [15]. None of the samples were repeat specimens.

\section{In vitro parasite culture}

3D7 (cloned from NF54 isolated at Schiphol airport Amsterdam, of unknown origin, probably Africa) and W2 (cloned in 1981 from mixed culture Sierra Leone SL I / CDC / Indochina III / CDC) clones of Plasmodium falciparum [20] obtained from the Malaria Research and Reference Reagent Resource Center (MR4) were used. These clones were maintained in continuous culture in an incubator at $37^{\circ} \mathrm{C}$, in a humid atmosphere with $5 \% \mathrm{CO}_{2}$. Parasites were grown on $\mathrm{RBC}$ rhesus $\mathrm{O}+$, at a hematocrit of $5 \%$ in RPMI 1640 added to $25 \mathrm{mM}$ Hepes, $50 \mu \mathrm{g} / \mathrm{mL}$ gentamycin, $0.1 \mathrm{mM}$ hypoxanthine, $20 \mathrm{mM} \mathrm{NaHCO} 3$ and $0.5 \%$ AlbuMax II, in culture flasks $\left(25 \mathrm{~cm}^{2}\right)$. Cultivated asynchronous parasites were serially diluted in noninfected blood from the biobank (from 100 parasites $/ \mu \mathrm{L}$ to 0.0001 parasites $/ \mu \mathrm{L}$ ) after washing out the culture medium to reduce the amount of soluble parasite DNA accumulated during the culture. Non-infected human blood was used as a negative control.

\section{LAMP test}

Whole blood specimens were processed using size exclusion chromatography by gravity flow to separate and purify nucleic acids. Sample effluent collected after the addition of the last buffer contains nucleic acids. The Illumigene Malaria PLUS DNA amplification assays were used (Meridian Bioscience Inc., Cincinnati, OH, USA) according to the manufacturer's specifications. This assay targets a 214 base pair sequence of a Plasmodium sp. mitochondrial DNA noncoding region that is conserved across Plasmodium falciparum, Plasmodium vivax, Plasmodium ovale, Plasmodium malariae, and Plasmodium knowlesi. The exact sequences of the 6 primers are not available from Meridian Inc. as part of intellectual property rights.

A by-product of amplification is magnesium pyrophosphate, which forms a white precipitate leading to a turbid reaction solution. Reaction solution absorbance characteristics are monitored by the Meridian illumipro-10 Incubator/Reader.

The Illumigene Malaria Test Device contains one lyophilized amplification reagent bead in each of two chambers: a test chamber with Plasmodium $s p$-specific 


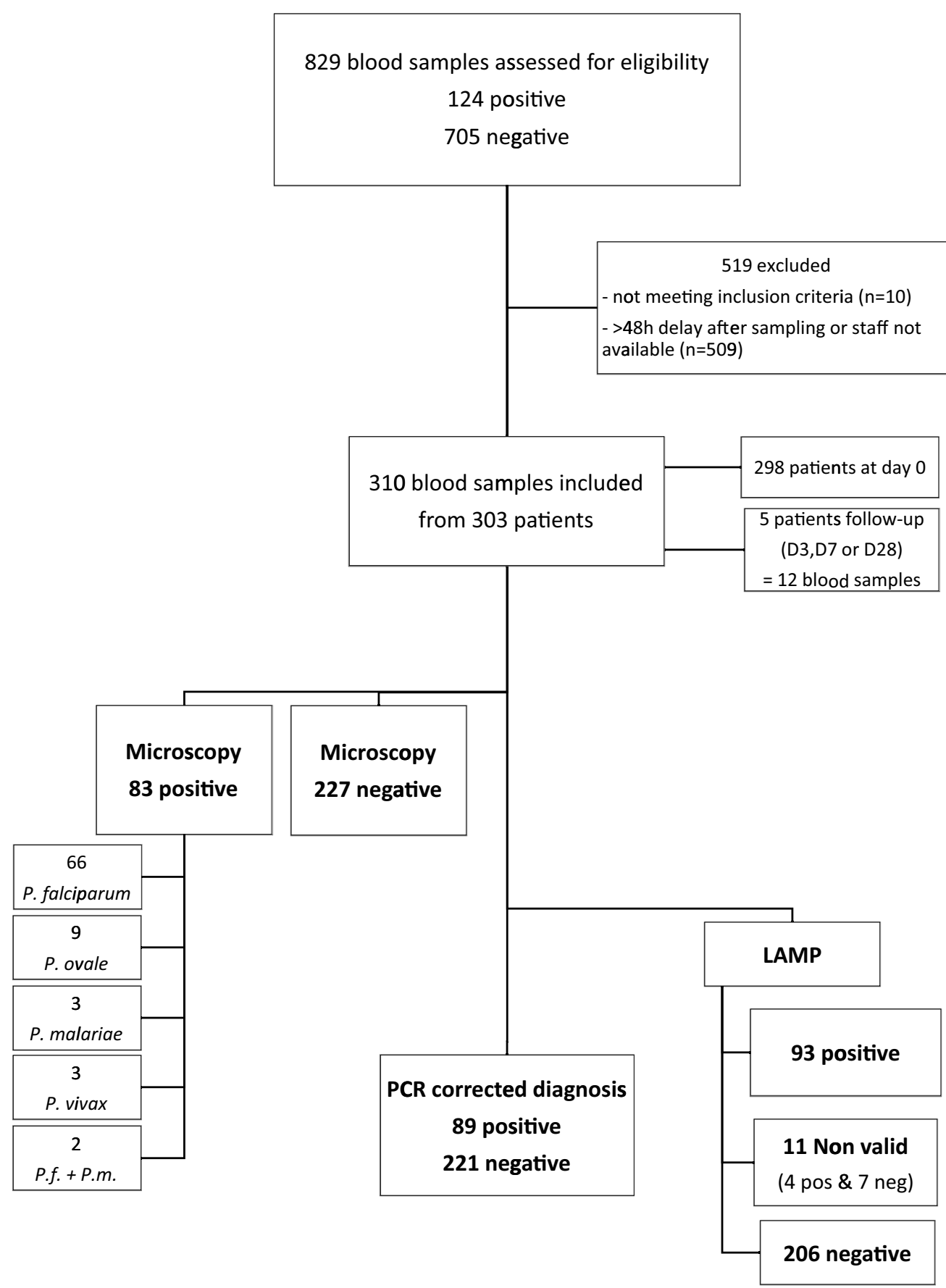

Figure 1. Study flow chart.

primers and a control chamber with human mitochondrial DNA specific primers as internal controls for the assay.

The reader calculates the change in light transmission between the beginning and the end of the test (Sf: $\mathrm{Si}$ ) and compares the ratio to a fixed cut-off value of $70 \%$. If the Sf: Si ratio is less than $70 \%$, the sample is reported positive. A different cut-off value (85\%) for the control chamber is used to determine the validity of the test (absence of amplification or presence of inhibitor). If the control test is invalid, the sample data (positive or negative) is not reported and thus not available.

\section{Real-time PCR}

DNA extraction was performed using the QIAamp DNA Mini kit (Qiagen, Hilden, Germany) according to the manufacturer's instructions, starting with $200 \mu \mathrm{L}$ of the parasite cultures. DNA was eluted with $50 \mu \mathrm{L}$ of elution buffer AE. Real-time PCR, using LightCycler technology (Roche Molecular Biochemicals, Mannheim, Germany) was performed with fluorescent SYBR Green I dye, as previously described [15]. The extracted DNA $(5 \mu \mathrm{L})$ was added to $15 \mu \mathrm{L}$ of reaction mixture containing $3 \mathrm{mM}$ of $\mathrm{MgCl} 2,0.5 \mu \mathrm{M}$ of each primer, and $2 \mu \mathrm{L}$ of LC Fast Start 
DNA Master SYBR-Green I buffer. Conditions for cycling were $95^{\circ} \mathrm{C}$ for 10 minutes, followed by 36 cycles at $95^{\circ} \mathrm{C}$ for 10 seconds, $58^{\circ} \mathrm{C}$ for 10 seconds and $72^{\circ} \mathrm{C}$ for 30 seconds, with monitoring of fluorescence at the end of the elongation steps. PCR product identity was confirmed with melting curves analysis. The melting program consisted of 1 cycle at $95^{\circ} \mathrm{C}$ for 2 seconds, $55^{\circ} \mathrm{C}$ for 20 seconds, and heating at $95^{\circ} \mathrm{C}$. A red blood cell control and a non-template control were included to test the amplification specificity and to allow detection of possible contamination of the PCR mixture, respectively. This method was routinely used for malaria diagnosis and clinically validated [15].

\section{Data analysis}

Data were pooled into double entry tables to compute the sensitivity, specificity, and positive and negative predictive values of each test, including $95 \%$ confidence intervals using MEDCALP statistical software available at https://www.medcalc.org/calc/diagnostic_test.php.

\section{Results}

\section{Blood samples from patients}

829 blood samples for malaria diagnosis were received during the one-year period. Most of the patients were adults presenting non-severe malaria $(n=721)$. None of the patients included had a fatal outcome. Roughly two thirds of these samples (519) were excluded from the study mainly due to unavailability of staff performing the LAMP test during the first 48 hours after blood sampling, since only three biologists out of six involved in malaria diagnosis were trained and certified to perform LAMP tests. This did not result in recruitment bias since availability was randomly based on the on-duty agenda of the team. Three hundred and ten blood samples from patients were included in the study. Clinical information and reference standard results were available to the performers during the LAMP test. LAMP results were later made available to the assessors of the reference test, but never used for the diagnosis of patients.

\section{Performance of the tests}

The absence of Plasmodium was determined from 227 samples using microscopic thick and thin blood smears examination. Among the 83 positive samples, species identification showed $P$. falciparum $(\mathrm{n}=66 ; 79.5 \%), P$. ovale $(\mathrm{n}=9 ; 10.9 \%), P$. vivax $(\mathrm{n}=3 ; 3.6 \%), P$. malariae $(\mathrm{n}=3 ; 3.6 \%)$ and 2 co-infections with $P$. falciparum and $P$. malariae (2.4\%). The high rate of Plasmodium falciparum versus non-falciparum species was expected since more than $80 \%$ of patients attending Lyon Hospital were infected in Africa, as observed for several decades.

Using real-time $\mathrm{PCR}, 89$ positive samples were detected. The 6 real-time PCR corrected positive diagnoses were samples from patient follow-up after treatment at days 7 and 28 .
Using LAMP methods, 93 samples gave positive results, including 4 false-positives, according to real-time PCR considered as the standard of truth. These falsepositive test results were considered to be due to DNA contamination during sample processing, as demonstrated by further tests. Using the LAMP Illumigen reader, eleven samples provided "invalid" results. While these tests were repeated once again, it was not possible to obtain a result to classify these samples with the LAMP method for unknown reasons. These samples were excluded from further analysis (Figure 1).

Performances of the method were calculated from 299 samples (excluding the 11 invalid results). Sensitivity and negative predictive values were $100 \%$ compared to microscopy and to real-time PCR (Table 1). Specificity and positive predictive value were slightly better compared to real-time PCR than to microscopy tests: 93.64 (CI95\%: 89.55 to 96.48$) / 98.13$ (CI95\%: 95.28 to 99.49 ) and 84.95 (CI95\%: 77.27 to 90.35 ) / 95.51 (CI95\%: 88.95 to $98.25)$, respectively.

While the sample size was limited, the four main Plasmodium species ( $P$. falciparum, $P$. ovale, P. malariae and $P$. vivax) were tested with parasitemia ranging from 450 to 315.000 parasites $/ \mu \mathrm{L}$. The LAMP method gave positive results for most of these species, except one $P$. vivax sample. We did not have epidemiological suspicion of Plasmodium knowlesi infection in our panel (patient contamination in South-East Asia and non-falciparum microscopic evidence), but all the parasites identified as Plasmodium malariae were confirmed by species-specific real-time PCR. We did not test $P$. knowlesi confirmed samples and pure gametocytes samples.

Six blood samples, considered as negative with microscopic methods and collected at day $28 \pm 3$ after treatment of patients presenting $P$. falciparum malaria were positive using Lamp, raising the issue of high sensitivity drawback for clinical diagnosis during the follow-up of a treated patient, opposed to the advantages of high sensitivity in pre-elimination settings. These patients were apyretic and asymptomatic, and slides remained classified as negative after control. The real-time PCRs were positive for these samples. As a result, these patients presented either sub-microscopic parasitemia or residual circulating DNA. No relapse was recorded for these patients at least two months after the end of 28-day follow-up.

\section{Parasite clones}

Serial dilutions of parasites from cultivated clones were inoculated to controlled negative human blood in order to obtain final parasite concentrations from 100 parasites/ $\mu \mathrm{L}$ to 0.0001 parasites $/ \mu \mathrm{L}$ (Table 2 ). LAMP tests were conducted in triplicate for each dilution and gave positive results up to a threshold of 0.1 parasites/ $\mu \mathrm{L}$ for both parasite clones, demonstrating a higher sensitivity of this method than that reported by the manufacturer ( 0.25 parasite $/ \mu \mathrm{L}, 3 \mathrm{D} 7$ clone). It should be noted that clones were washed three times before dilution in order to avoid 
Table 1. Performance comparison between LAMP and microscopy or real-time PCR. Sensitivity, specificity, positive predictive value and negative predictive value were calculated based on 299 samples, excluding the 11 invalid results from LAMP. The number of samples used for microscopy are 79 positive ( $83-4$ invalid excluded) and 220 negative (227-7 invalid excluded). The number of samples used for PCR are 85 positive ( $89-4$ invalid excluded) and 214 negative (221-7 invalid excluded).

\begin{tabular}{|c|c|c|c|c|c|c|c|}
\hline & & \multicolumn{3}{|c|}{ Microscopy } & \multicolumn{3}{|c|}{ Real-time PCR } \\
\hline & & + & - & total & + & - & total \\
\hline \multirow[t]{4}{*}{ LAMP } & + & 79 & 14 & 93 & 85 & 4 & 89 \\
\hline & - & 0 & 206 & 206 & 0 & 210 & 210 \\
\hline & & 79 & 220 & 299 & 85 & 214 & 299 \\
\hline & & \multicolumn{3}{|c|}{ Versus microscopy } & \multicolumn{3}{|c|}{ Versus real-time PCR } \\
\hline \multicolumn{2}{|c|}{ LAMP performance } & $\%$ & \multicolumn{2}{|c|}{$95 \%$ confidence interval $(\%)$} & $\%$ & \multicolumn{2}{|c|}{$95 \%$ confidence interval $(\%$} \\
\hline \multicolumn{2}{|c|}{ Sensitivity } & 100 & \multicolumn{2}{|c|}{95.55 to 100} & 100 & \multicolumn{2}{|c|}{95.75 to 100} \\
\hline \multicolumn{2}{|c|}{ Specificity } & 93.64 & \multicolumn{2}{|c|}{89.55 to 96.48} & 98.13 & \multicolumn{2}{|c|}{95.28 to 99.49} \\
\hline \multicolumn{2}{|c|}{ Positive predictive value } & 84.95 & \multicolumn{2}{|c|}{77.27 to 90.35} & 95.51 & \multicolumn{2}{|c|}{88.95 to 98.25} \\
\hline \multicolumn{2}{|c|}{ Negative predictive value } & 100 & \multicolumn{2}{|l|}{ n.a. } & 100 & \multicolumn{2}{|l|}{ n.a. } \\
\hline \multicolumn{2}{|c|}{ Positive likelihood ratio } & 15.7 & \multicolumn{2}{|l|}{ n.a. } & 53.5 & \multicolumn{2}{|l|}{ n.a. } \\
\hline
\end{tabular}

Table 2. Limit of detection of the Illumigen Malaria plus LAMP method. Serial dilutions of Plasmodium falciparum in vitro cultivated clones 3D7 and W2 were tested using light microscopy (Giemsa stained thin blood smears), real-time PCR and LAMP Illumigen malaria. (inv. = invalid)

\begin{tabular}{|c|c|c|c|c|c|c|c|}
\hline \multirow{3}{*}{$\begin{array}{l}\text { Plasmodium } \\
\text { falciparum clones } \\
\text { 3D7 }\end{array}$} & \multicolumn{2}{|c|}{ Parasitemia (dilutions from thin blood smears) } & \multirow[t]{2}{*}{$\begin{array}{l}\text { Real-time PCR } \\
\text { (35 cycles) }\end{array}$} & \multicolumn{4}{|c|}{$\begin{array}{l}\text { LAMP } \\
\text { Illumigen Malaria } \\
\text { (Meridian) }\end{array}$} \\
\hline & \multirow{2}{*}{$\frac{\%}{0.002}$} & Parasites $/ \mu \mathrm{L}$ & & \multicolumn{3}{|c|}{ Repeated measures } & \multirow{2}{*}{$\begin{array}{l}\text { LAMP interpretation } \\
\text { Positive }\end{array}$} \\
\hline & & 100 & Positive & inv. & + & + & \\
\hline- & 0.0002 & 10 & Positive & + & + & + & Positive \\
\hline- & 0.00002 & 1 & Positive & + & inv. & + & Positive \\
\hline- & 0.000002 & 0.1 & Positive & + & - & + & Positive \\
\hline- & 0.0000002 & 0.01 & Positive & - & - & - & Negative \\
\hline- & 0.00000002 & 0.001 & Negative & - & - & - & Negative \\
\hline- & 0.00000002 & 0.0001 & Negative & - & - & - & Negative \\
\hline W2 & 0.002 & 100 & Positive & + & + & inv. & Positive \\
\hline- & 0.0002 & 10 & Positive & + & + & inv. & Positive \\
\hline- & 0.00002 & 1 & Positive & + & + & + & Positive \\
\hline- & 0.000002 & 0.1 & Positive & + & + & + & Positive \\
\hline- & 0.000002 & 0.01 & Positive & - & - & - & Negative \\
\hline- & 0.0000002 & 0.001 & Negative & - & - & - & Negative \\
\hline- & 0.00000002 & 0.0001 & Negative & - & - & - & Negative \\
\hline
\end{tabular}

contamination with soluble parasite DNA accumulated during the culture process. While time limits (below 2 minutes) for processing samples before starting the run were strictly respected, we faced rare occurrence of invalid results with the highest concentration of some samples. A limit of detection of 0.01 parasites $/ \mu \mathrm{L}$ was obtained for both clones using real-time PCR with the same batch of dilution and the same volume of samples before DNA extraction.

\section{Discussion}

The goal of this study was to evaluate over a one-year period, the advantages of a commercially available LAMP diagnostic test for malaria compared to light microscopy and real-time PCR, using standard laboratory conditions on a daily basis in a non-endemic area hospital. A secondary objective was to evaluate the potential of this method to be used in a larger study to test its relevance for 
malaria screening in clinical laboratories on call conditions during the night. Two different versions of the test are available from the provider, with different sensitivities. We only tested the highest sensitivity kit [13], requiring more analytical steps but expected to have a lower detection threshold, since one of the objectives was to evaluate the potential of this method to be used as a firstline diagnostic test when expert microscopist are not available. Sensitivity and specificity of LAMP compared to microscopy have already been shown to be $98 \%$ and $97 \%$, respectively from a meta-analysis of molecular methods for malaria diagnosis [24]. A recent study from Canada [25] has shown a sensitivity of $100.0 \%$ [95.1$100.0 \%]$ and specificity of $91.5 \%$ [81.3 - 97.2\%] versus reference microscopy. Similar remarkable results were obtained in this study (sensitivity of $100 \%$ [95.55 to 100\%] and specificity of $93.64 \%$ [89.55 to $96.48 \%]$ versus microscopy. The same commercially available test was evaluated in endemic areas [13], showing sensitivity of $97.2 \%$ [92.6 to $99.1 \%$ ] and specificity of $87.7 \%$ [76.6 to $94.2 \%$ ] versus PET-PCR, while results presented here showed sensitivity of $100 \% \quad[95.75 \%$ to $100 \%]$ and specificity of $98.13 \%$ [95.28\% to $99.49 \%]$ compared to real-time PCR. Several in-house methodological improvements of the LAMP method have been tested recently in different conditions, precluding significant comparison with a commercially available test.

A systematic review and meta-analysis of loopmediated isothermal amplification for malaria diagnosis is in preparation to compare the results from all available studies (Prospero 2017 CRD42017075186: http://www. crd.york.ac.uk/PROSPERO/display record.php?ID=CRD 42017075186)

Moreover, we tested the limit of detection of the Meridian Malaria Plus test with serial dilutions of cultivated clones synchronized at young trophozoite stages just before dilutions (3D7: 95\% young trophozoites; W2: $75 \%$ young trophozoites). Culture samples were washed out three times before mixing with negative blood from the blood bank to drastically reduce the amount of free DNA. We observed a limit of detection of 0.1 parasites $/ \mu \mathrm{L}$, which is 2.5 times lower than the LOD provided by the manufacturer, and 10 times lower than the LOD of the real-time PCR method developed a decade ago in the laboratory. The LOD indicated by the manufacturer was obtained from a "theoretical probability" of obtaining positive results, as indicated in the handbook. It should be mentioned that in the same document, the LOD for Plasmodium vivax is indicated as 0.063 parasites $/ \mu \mathrm{L}$, which needs to be documented further. We did not test the LOD for non-falciparum species since cultures are not available, and dilutions of blood from infected patients should be associated with contamination by circulating parasite DNA, leading to false results.

In our laboratory, the method was easy to perform without requiring more than one hour training, and provided reliable data. It was simple to test one to four samples in the same run, including systematically a negative control, and to perform two runs in parallel on the same machine, when needed. The machine is small, linked to a dedicated printer, and did not require any connection except a power supply. The sample preparation required 4 steps of 2 minutes, and the amplification run was completed within 40 minutes, leading to a time-to-result period of less than one hour. Taken together, the practicality of the machine and the test are good, but should be limited to laboratory settings, including those in endemic areas, with a sufficient level of equipment and biological skills. The tested LAMP method (Illumigene Malaria Plus test, Meridian Bioscience Inc., Cincinnati, OH, USA) is not suitable for point-of-care use since it requires blood sample preparation and measures against DNA cross-contamination. However, the LAMP methodology could probably be adapted to field conditions, provided simplification of the process could be obtained, without decreasing sensitivity and negative predictive value $[5,6,26]$.

The most disappointing situation is the "invalid" code, without the possibility of understanding the reason of this failure (high parasitemia, DNA amplification inhibitor, delay in the extraction process). This invalid code meant that the biologist had to perform other diagnostic tests (microscopic, RDT, PCR), after having spent one hour on the method.

One drawback of this method is that the result is restricted to a positive/negative outcome, with no information on species identification and parasite burdens. Thus, this method is not eligible as a single diagnostic tool in non-endemic areas where all Plasmodium species can be expected from imported cases. However, in many African field areas, the high majority of transmitted parasites are Plasmodium falciparum, with a limited risk of other species infection (mainly $P$. ovale and $P$. malariae, and rare occurrence of $P$. vivax in sub-Saharan Africa). Considering that the main issue to be addressed is the detection of the lowest parasitemia, the lack of information on species identification and parasite burden appears not to be a definitive limitation for this test. However, other LAMP tests have been developed to discriminate Plasmodium species $[9,11,21,27]$.

We did not test the detectability of pure sexual parasite stages and thus we cannot address the question of whether the LAMP method is suitable for detection of gametocyte carriers with the goal of malaria elimination. This question needs to be addressed by further studies, while authors have reported interesting results [7].

The highest benefit of this test is its negative predictive value. In emergency situations, this LAMP method will help to exclude patients inadequately suspected of malaria without any more requirements for expert microscopic examination of stained smears. In non-endemic areas, the positivity rate of suspected malaria is highly dependent on the experience of clinicians on call, and high variations may be encountered. However, it could be speculated that a vast majority of malaria tests remain negative. In our experience, a mean of $85 \%$ of the 850 malaria tests performed per year for patients suspected of imported malaria are negative. This means that using the LAMP test will reduce the need for a majority of microscopic and 
RDTs diagnosis, and thus considerably decrease the burden of Quality Assurance requirements for nonspecialized laboratories.

In case of positivity, since the subspecies diagnosis is required to adapt first-line treatment in many countries, microscopic tests will be needed. During the night, or during on call periods, a positive LAMP test could be supplemented by a species-specific RDT, to obtain a nonspecialized diagnosis of falciparum or non-falciparum malaria in less than one hour. This emergency diagnosis can be supplemented with smear examinations on the next day to confirm the diagnosis, the species identification, and to determine parasitemia. It should be noted that parasitemia levels are important in case of high values, over the threshold of $4-5 \%$, which remains relatively uncommon. However, in case of high parasitemia, clinical signs of severity are a more reliable marker of a poor outcome than parasitemia. Treatment failures due to complete resistance to the drug used are very uncommon, while resistance to artemisinin derivatives is now a major issue in South-East Asia. Therefore, the usefulness of measuring parasitemia for treatment follow-up has to be balanced with body temperature and clinical presentation.

The basic cost of this test is high in first analysis (approximately USD 25 per single test). However, this high cost should be considered with the fact that the reader may be provided for free or with a very limited cost compared to PCR machines, and that no other reagents are needed. The test can be performed by a non-specialized technician, and since the result is negative/positive, no medical expertise is needed for interpretation. Since the cost of expert human resources is a major part of the global cost of a biological test, this simplification should be taken into consideration for estimating the real cost of the LAMP malaria test. Based on this consideration, value for money and cost-effectiveness appeared acceptable.

Simplicity, robustness, high negative predictive value, high positive likelihood ratios, and the lack of sophisticated equipment suggest that the method could legitimately add value or replace usual microscopic methods for the diagnosis of malaria in laboratories performing the initial emergency screening for imported malaria cases in nonendemic countries. The clinical utility of the Malaria Plus Lamp test from Meridian, as recently defined [2], should be considered positive.

Acknowledgments. We thank Prof. Christian Chidiac and Prof. François Peyron for their continuous support.

The authors would also like to thank Manon Lleres, Charlotte Pratlong, Sarra-Nadia Karoui and Corentin Achard for their invaluable participation in the diagnosis using microscopic methods. We thank the technicians from the Lyon Hospital Laboratory who performed slide staining and RDT tests. We thank Élodie Bonhomme from Meridian Inc. for training and technical support. We thank Silene Cronenberger from HCL.

\section{Conflict of interest}

The Associate Editor of Parasite, Stéphane Picot, is one of the authors of this manuscript. COPE (Committee on Publication Ethics, http://publicationethics.org), to which Parasite adheres, advises special treatment in these cases. In this case, the peer-review process was handled by the Editor-in-Chief.

Meridian Inc. provided the machine and 50 Malaria plus tests for the study, but none of the Meridian staff were involved in the study procedure, data analysis, and manuscript writing.

\section{References}

1. Billo MA, Diakité M, Dolo A, Diallo M, Poudiougou B, Diawara SI, Johnson ES, Rice JC, Krogstad DJ, Doumbo OK. 2013. Inter-observer agreement according to malaria parasite density. Malaria Journal, 12, 335.

2. Bossuyt PMM, Reitsma JB, Linnet K, Moons KGM. 2012. Beyond diagnostic accuracy: the clinical utility of diagnostic tests. Clinical Chemistry, 58, 1636-1643.

3. Britton S, Cheng Q, Grigg MJ, Poole CB, Pasay C, William T, Fornace K, Anstey NM, Sutherland CJ, Drakeley C, McCarthy JS. 2016. Sensitive detection of Plasmodium vivax using a high-throughput, colourimetric loop mediated isothermal amplification (HtLAMP) platform: a potential novel tool for malaria elimination. PLoS Neglected Tropical Diseases, 10, e0004443.

4. Britton S, Cheng Q, Grigg MJ, William T, Anstey NM, McCarthy JS. 2016. A sensitive, colorimetric, highthroughput loop-mediated isothermal amplification assay for the detection of Plasmodium knowlesi. American Journal of Tropical Medicine and Hygiene, 95, 120-122.

5. Britton S, Cheng Q, McCarthy JS. 2016. Novel molecular diagnostic tools for malaria elimination: a review of options from the point of view of high-throughput and applicability in resource limited settings. Malar Journal, 15, 88.

6. Britton S, Cheng Q, Sutherland CJ, McCarthy JS. 2015. A simple, high-throughput, colourimetric, field applicable loop-mediated isothermal amplification (HtLAMP) assay for malaria elimination. Malaria Journal, 14, 335.

7. Buates S, Bantuchai S, Sattabongkot J, Han E-T., Tsuboi T, Udomsangpetch R, Sirichaisinthop J, Tan-ariya P. 2010. Development of a reverse transcription-loop-mediated isothermal amplification (RT-LAMP) for clinical detection of Plasmodium falciparum gametocytes. Parasitology International, 59, 414-420.

8. Cohen JF, Korevaar DA, Altman DG, Bruns DE, Gatsonis CA, Hooft L, Irwig L, Levine D, Reitsma JB, de Vet HC, Bossuyt PM. 2016. STARD 2015 guidelines for reporting diagnostic accuracy studies: explanation and elaboration. Bristish Medical Journal Open, 6: 012799.

9. Cuadros J, Martin Ramírez A, González IJ, Ding XC, Perez Tanoira R, Rojo-Marcos G, Gómez-Herruz P, Rubio JM. 2017. LAMP kit for diagnosis of non-falciparum malaria in Plasmodium ovale infected patients. Malaria Journal, 16, 20.

10. Eibach D, Traore B, Bouchrik M, Coulibaly B, Coulibaly N, Siby F, Bonnot G, Bienvenu AL, Picot S. 2013. Evaluation of the malaria rapid diagnostic test VIKIA malaria $\mathrm{Ag} \mathrm{Pf} /$ PanTM in endemic and non-endemic settings. Malaria Journal, 12, 188.

11. Kongkasuriyachai D, Yongkiettrakul S, Kiatpathomchai W, Arunrut N. 2017. Loop-Mediated Isothermal Amplification and LFD Combination for detection of Plasmodium falciparum and Plasmodium vivax. Methods in Molecular Biology, 1572, 431-443. 
12. Lucchi NW, Demas A, Narayanan J, Sumari D, Kabanywanyi A, Kachur SP, Barnwell JW, Udhayakumar V. 2010. Real-time fluorescence loop mediated isothermal amplification for the diagnosis of malaria. PLoS ONE, 5, e13733.

13. Lucchi NW, Gaye M, Diallo MA, Goldman IF, Ljolje D, Deme AB, Badiane A, Ndiaye YD, Barnwell JW, Udhayakumar V, Ndiaye D. 2016. Evaluation of the Illumigene Malaria LAMP: A robust molecular diagnostic tool for malaria parasites. Scientific Reports, 6, 36808.

14. Mohon AN, Lee LD-Y., Bayih AG, Folefoc A, Guelig D, Burton RA, LaBarre P, Chan W, Meatherall B, Pillai DR. 2016. NINA-LAMP compared to microscopy, RDT, and nested PCR for the detection of imported malaria.Diagnostic Microbiology and Infectious Diseases, 85, 149-153.

15. de Monbrison F, Angei C, Staal A, Kaiser K, Picot S. 2003. Simultaneous identification of the four human Plasmodium species and quantification of Plasmodium DNA load in human blood by real-time polymerase chain reaction. Transactions of the Royal Society of Tropical Medicine and Hygiene, 97, 387-390.

16. Newby G, Bennett A, Larson E, Cotter C, Shretta R, Phillips AA, Feachem RG. 2016. The path to eradication: a progress report on the malaria-eliminating countries. Lancet, 387, 1775-1784

17. Notomi T, Okayama H, Masubuchi H, Yonekawa T, Watanabe K, Amino N, Hase T. 2000. Loop-mediated isothermal amplification of DNA. Nucleic Acids Research, 28, E63.

18. Odaga J, Sinclair D, Lokong JA, Donegan S, Hopkins H, Garner P. 2014. Rapid diagnostic tests versus clinical diagnosis for managing people with fever in malaria endemic settings. Cochrane Database Systematic Review, C D008998.

19. Oriero EC, Jacobs J, Geertruyden J-PV, Nwakanma D, D'Alessandro U. 2015. Molecular-based isothermal tests for field diagnosis of malaria and their potential contribution to malaria elimination. Journal of Antimicrobial Chemotherapy, $70,2-13$.

20. Picot S, M Loiseau P, Bienvenu A-L. 2014. New antimalarial drugs: who cares? Current Topics in Medicinal Chemistry, 14, 1637-1642.

21. Piera KA, Aziz A, William T, Bell D, González IJ, Barber BE, Anstey NM, Grigg MJ. 2017. Detection of Plasmodium knowlesi,Plasmodium falciparumandPlasmodium vivaxusing loop-mediated isothermal amplification (LAMP) in a coendemic area in Malaysia. Malaria Journal, 16, 29
22. Polley SD, González IJ, Mohamed D, Daly R, Bowers K, Watson J, Mewse E, Armstrong M, Gray C, Perkins MD, Bell D, Kanda H, Tomita N, Kubota Y, Mori Y, Chiodini PL, Sutherland CJ. 2013. Clinical evaluation of a loop-mediated amplification kit for diagnosis of imported malaria. Journal of Infectious Diseases, 208, 637-644

23. Poon LLM, Wong BWY, Ma EHT, Chan KH, Chow LMC, Abeyewickreme W, Tangpukdee N, Yuen KY, Guan Y, Looareesuwan S, Peiris JS. 2006. Sensitive and inexpensive molecular test for falciparum malaria: detecting Plasmodium falciparum DNA directly from heat-treated blood by loop-mediated isothermal amplification. Clinical Chemistry, 52, 303-306.

24. Roth JM, Korevaar DA, Leeflang MMG, Mens PF. 2016. Molecular malaria diagnostics: A systematic review and meta-analysis. Critical Reviews in Clinical Laboratory Sciences, 53, 87-105.

25. Rypien C, Chow B, Chan W, Church D, Pillai DR. Detection of Plasmodium spp. infection by the illumigene ${ }^{\circledR}$ Malaria assay compared to reference microscopy and realtime PCR. 2017. Journal of Clinical Microbiology, 55, 30373045.

26. Sema M, Alemu A, Bayih AG, Getie S, Getnet G, Guelig D, Burton R, LaBarre P, Pillai DR. 2015. Evaluation of non-instrumented nucleic acid amplification by loopmediated isothermal amplification (NINA-LAMP) for the diagnosis of malaria in Northwest Ethiopia. Malaria Journal, 14, 44.

27. Singh R, Singh DP, Savargaonkar D, Singh OP, Bhatt RM, Valecha N. 2017. Evaluation of SYBR green I based visual loop-mediated isothermal amplification (LAMP) assay for genus and species-specific diagnosis of malaria in $P$. vivax and $P$. falciparum endemic regions. Journal of Vector Borne Diseases, 54, 54-60.

28. Visser T, Daily J, Hotte N, Dolkart C, Cunningham J, Yadav P. 2015. Rapid diagnostic tests for malaria. Bulletin World Health Organization, 93, 862-866.

29. White NJ, Pukrittayakamee S, Hien TT, Faiz MA, Mokuolu OA, Dondorp AM. 2014. Malaria. Lancet, 383, 723-735.

30. Wilson ML. 2013. Laboratory diagnosis of malaria: conventional and rapid diagnostic methods. Archives of Pathology and Laboratory Medicine, 137, 805-811.

31. Zimmerman PA, Howes RE. 2015. Malaria diagnosis for malaria elimination. Current Opinion on Infectious Diseases, 28, 446-454.

Cite this article as: Ponce C, Kaczorowski F, Perpoint T, Miailhes P, Sigal A, Javouhey E, Gillet Y, Jacquin L, Douplat M, Tazarourte K, Potinet V, Simon B, Lavoignat A, Bonnot G, Sow F, Bienvenu A-L, Picot S. 2017. Diagnostic accuracy of loopmediated isothermal amplification (LAMP) for screening patients with imported malaria in a non-endemic setting. Parasite 24, 53 
O PARASTE

An international open-access, peer-reviewed, online journal publishing high quality papers on all aspects of human and animal parasitology

Reviews, articles and short notes may be submitted. Fields include, but are not limited to: general, medical and veterinary parasitology; morphology, including ultrastructure; parasite systematics, including entomology, acarology, helminthology and protistology, and molecular analyses; molecular biology and biochemistry; immunology of parasitic diseases; host-parasite relationships; ecology and life history of parasites; epidemiology; therapeutics; new diagnostic tools.

All papers in Parasite are published in English. Manuscripts should have a broad interest and must not have been published or submitted elsewhere. No limit is imposed on the length of manuscripts.

Parasite (open-access) continues Parasite (print and online editions, 1994-2012) and Annales de Parasitologie Humaine et Comparée (1923-1993) and is the official journal of the Société Française de Parasitologie. 